\title{
Diário do Ano InTERnacional da Químıca 2011
}

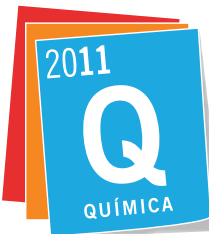

O

Diário do Ano Internacional da Química pretende compilar de uma forma resumida o conjunto de actividades que foram realizadas no âmbito das comemorações do Ano Internacional da Química e do Centenário da SPQ. São inúmeras e variadas, sendo por isso apresentadas de uma forma cronológica.

\section{JANEIRO}

CONFERÊNCIAS:

Golden Chemistry - O ciclo de conferências GOLDEN CHEMISTRY levou à Universidade da Madeira uma série de personalidades ligadas à Química.

Hybrid Nanofibers for Environmental and Catalytic Applications Xiangyang Shi (Cátedra FCT/UMa/ Santander) - 28 Janeiro

A I\&D no medicamento - da Química ao Paciente - José Redondo (BIAL, Portugal) - 6 Abril

Pulse Sensing using Tunable Nanopores - Dr. Geoff Willmott (Industrial Research Limited, Wellington, New Zealand) - 19 Abril

Produtos Audiovisuais: Entrevista com o Dr Mário Nuno de Matos Sequeira Berberan e Santos, actual Presidente da Sociedade Portuguesa de Química - TVI

http://www.tvi.iol.pt/mediacenter. html?mul_id=13414826\&load=3\&pagi na $=1 \&$ pos $=0$

QuímICA PARA TODOS: O "Química para Todos" engloba um conjunto de actividades que tem por objectivo divulgar e sensibilizar miúdos e graúdos para a importância da Química no nosso dia-a-dia. Este projecto inclui a publicação de uma coluna na imprensa, a realização de actividades experimentais nos laboratórios do Departamento de Química da Universidade de Évora, nas escolas da região, na Feira de São João e noutros locais públicos, e ainda a participação nas actividades da Universidade Sénior Túlio Espanca / Escola Popular da Universidade de Évora e na dinamização de visitas de estudo aos laboratórios de Química.

Coluna na Imprensa: Esta coluna, publicada no regional "Diário do Sul" e no jornal online da Universidade de
Évora "UELINE", tem como objectivo a divulgação da Química na perspectiva do quotidiano e das actividades científicas do Centro de Química de Évora e do Departamento de Química da Escola de Ciências e Tecnologia da Universidade de Évora numa linguagem acessível a todos.

$1^{\text {a }}$ Edição - 5 Janeiro

Actividades Experimentais: Nestas actividades, um conjunto de experiências químicas simples, demonstrativas e interactivas, ilustram-se fenómenos químicos, esclarecem-se dúvidas e desperta-se a curiosidade dos mais pequenos e não só...

Universidade Sénior Túlio Espanca / Escola Popular da Universidade de Évora: Como o saber não ocupa lugar nem escolhe idades, a Química também está presente na Universidade Sénior Túlio Espanca / Escola Popular da Universidade de Évora com um conjunto de actividades destinadas àqueles que, sendo menos jovens, mantêm o gosto pelo saber e o prazer da descoberta!

Os ácidos e as bases no dia-a-dia Professora Doutora Margarida Figueiredo - 12 Janeiro

As reacções de oxidação-redução no dia-a-dia - Professora Doutora Margarida Figueiredo - 9 Fevereiro

Visitas de Estudo: As Escolas vão à Universidade que abre as portas dos seus laboratórios para as tradicionais visitas de estudo onde se pode "espreitar" o mundo da Química e o desenrolar de experiências in-situ.

Visita de estudo: Escola EB2,3 c/S Dr. Hernâni Cidade (Redondo) 13 Janeiro

Visita de estudo: Escola Secundária com $3^{\circ}$ Ciclo do E.B. Moura 27 Janeiro

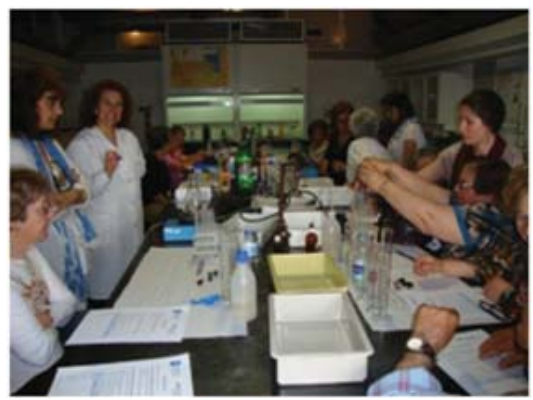

Univ. Sénior Túlio Espanca: Os ácidos e as bases no dia-a-dia

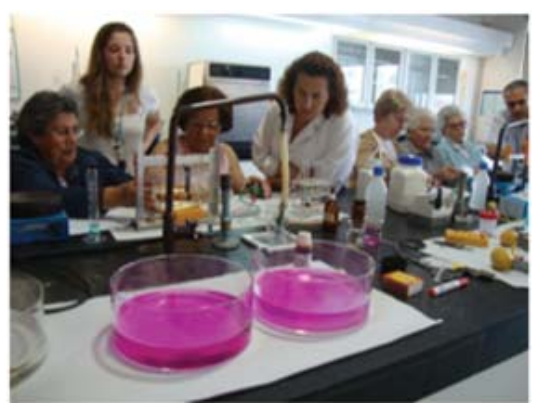

Univ. Sénior Túlio Espanca: As reacções de oxidação - redução no dia-a-dia

Exposições e outros Eventos: Química por Tabela 2.0 - Novo espectáculo para comunicação de ciência que procura fazer a ligação constante com a química que nos rodeia no quotidiano. Consiste numa sequência de transformações químicas curiosas, surpreendentes, e por vezes espectaculares, onde são explorados conceitos de ácido-base, oxidação-redução, precipitação, combustão, complexação, quimioluminescência, entre outros. As alterações de cor e de estado físico proporcionam efeitos visuais apelativos estimulando a participação do público.

«Química por Tabela 2.0» mostra que «por tabela» é possível aprender química fora da sala de aula.

Fábrica CCVA - 6 Janeiro

Produtos Audiovisuais: Elvira Fortunato (FCT UNL) no Jornal das 9 - SIC

"Electrónica de Baixo Custo" - Investigadores portugueses desenvolvem o primeiro transístor feito de papel 
CONFERÊNCIAS:

Conferências do Centro de Química de Évora (CCQE) - Ciclo de Conferências de índole científica destinadas à comunidade académica em geral e, em particular, aos alunos dos cursos de formação graduada, pós-graduada e investigadores nas áreas em que a Química desempenha um papel fundamental. São convidados especialistas nacionais e estrangeiros em várias áreas da Química, abordando aspectos fundamentais desta ciência, sua interacção com outras áreas do conhecimento e sua importância no contexto da sociedade moderna.

Development and Applications of Biomaterials - Perumal Ramasamy (Anna University; India) - 11 Janeiro

Silicatos e Metal Organic Frameworks microporosos e fotoluminescentes - João Carlos Rocha (UA) - 21 Janeiro

Actividades LABORATORIAIS / VisitAS DE EsTUdO: Vamos Kimikar - Entre 12 de Janeiro e Junho houve 16 sessões laboratoriais, às quartas-feiras de tarde, envolvendo mais de 400 alunos do $8^{\circ}$ e $9^{\circ}$ anos provenientes de escolas de Braga, Viana do Castelo, Fafe, Póvoa de Lanhoso, Ponte de Lima e Ponte da Barca.

EXPOSIÇÕES E OUTROS EVENTOS: Women sharing a chemical moment in time - As mulheres do DQB da Faculdade de Ciências da Universidade de Lisboa e do DQ da Universidade de Aveiro aderiram, no dia 18 de Janeiro, à iniciativa "Women Sharing a Chemical Moment in Time" no prélançamento do Ano Internacional da Química. Desenvolvimento no QUíMICA 120.

AcÇõES DE FORMAÇÃO / WORKSHOPS: Química em Micro-Escala - Oficina de Formação de Professores: $2^{\mathrm{a}}$ Edição de uma Oficina de Formação acreditada para Professores de Ciências Físico-Químicas: kits para grande Química em pequenas dimensões - 22 Janeiro

ExPOSIÇÕES E OUTROS EVENTOS: Sessão de Abertura "QUI365 - 365 dias com a Química" - O Departamento de Química da UC realizou, no dia 25

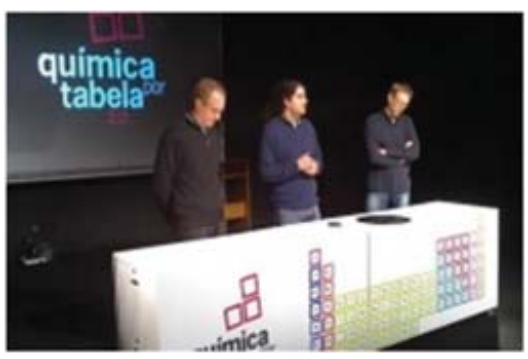

Paulo Ribeiro Claro e Brian Goodfellow

de Janeiro, a Sessão de Abertura do "QUI365 - 365 dias com a Química", iniciativa que pretende celebrar ao longo de 2011 a declaração da Unesco de Ano Internacional da Química.

\section{Programa}

14:30h - "The Portuguese Science Indicators: a case of success and contradictions" Prof. Doutor Rui Fausto Lourenço 15:15h-Apresentação do livro "Dorothy Crowfoot Hodgkin" da Professora Raquel Gonçalves-Maia apresentada pelo Prof. Doutor Sebastião Formosinho

ExposiçõEs e outros Eventos: Cerimónia Oficial de Lançamento do AIQ2011 - Sede UNESCO, Paris - 27 Janeiro. Desenvolvimento no QUíMICA 120.

ExPOSIÇÕES E OUTROS EVEntos: Cerimónia de Lançamento do AIQ 2011 na Universidade do Minho - Esta sessão marcou oficialmente a abertura do Ano Internacional da Química e decorreu no Auditório da ECUM, em simultâneo com a cerimónia mundial na sede da UNESCO (fez-se a transmissão em directo da cerimónia em Paris). A sessão teve início às 10:00h e foi precedida por uma conferência de imprensa.

\section{Programa}

9:30h - Conferência de imprensa 10:00h - Cerimónia de abertura, que incluiu as palestras: Pode a Química ser o que não é? - Prof. Miguel Castanho
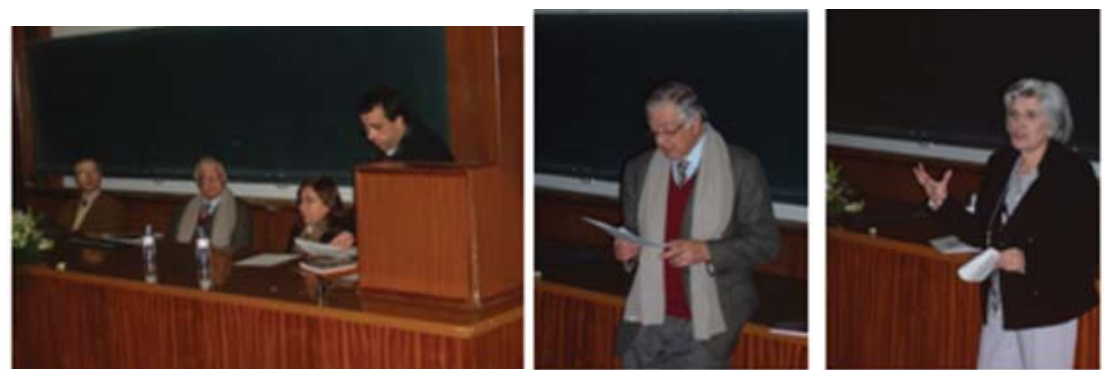

Da esquerda para a direita: Mesa de Honra; Apresentação do livro - Sebastião Formosinho e Raquel
Gonçalves-Maia, a Autora Da esquerda para a direita: Mesa de Honra; Apresentação do livro - Sebastião Formosinho e Raquel
Gonçalves-Maia, a Autora

(FML) AIQ - Marie, Irène, Dorothy, Ada - Profa Raquel Gonçalves Maia (FCUL) e a apresentação do livro sobre Dorothy Hodgkin, da autoria da Prof $^{a}$ Raquel Gonçalves Maia.

EXPOSIÇÕES E OUTROS EVENTOS: Lançamento oficial do programa AIQ2011 em Aveiro - A Fábrica Centro Ciência Viva de Aveiro e o Departamento de Química da Universidade de Aveiro são parceiros na celebração do Ano Internacional da Química. Prometem 12 meses de actividade formativa e lúdica em torno da química como forma de despertar o gosto pela disciplina e também como forma de dar nova imagem a uma área do conhecimento marcada pelo distanciamento dos alunos nos últimos anos.

Data: 27 Janeiro

ExPOSIÇÕES E OUTROS EVENTOS: Cerimónia de Lançamento do AIQ 2011 na Faculdade de Engenharia da Universidade do Porto - Departamento de Engenharia Química - A

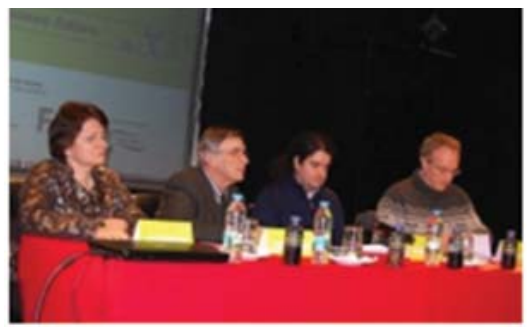

Lançamento oficial do programa do AIQ em Aveiro 
Cerimónia de lançamento ocorreu em simultâneo com a abertura oficial do AIQ na UNESCO em Paris. A actividade decorreu num ambiente informal com a apresentação de 3 comunicações sobre a importância da Química nas outras áreas da Engenharia.

Portals Dedicados: Divulgação do Blogue "Química para Todos"

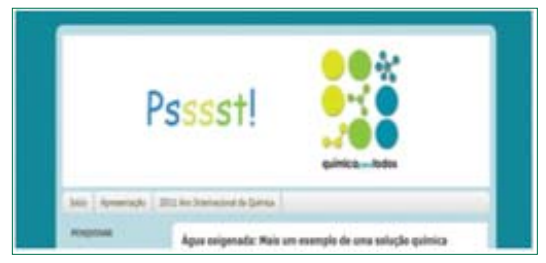

Blogue "Química para Todos"

EXPOSIÇÕES E OUTROS EVENTOS:

Lançamento do programa do AIQ no ISEL - Distribuição de um folheto de divulgação sobre a importância da Química no quotidiano e a contribuição dos desenvolvimentos recentes desta Ciência para o bem-estar da sociedade. Afixação de posters com a mesma temática pelas várias áreas departamentais do ISEL - 27 Janeiro

Aventuras de Moléculas de Água no Teu Corpo - Diálogos entre um adolescente e um professor - Centro Ciência Viva de Coimbra - 27 de Janeiro

Abertura Oficial do AIQ no DQB Porto de Honra - Conferência "A Química vista por...Dorothy Hodgkin, prémio Nobel" - Raquel Gonçalves Maia (15h - Anfiteatro DQB FCUP) Porto de Honra - 28 Janeiro

Inauguração das Comemorações do Ano Internacional da Química, Anunciado pelo Magnífico Reitor da UBI - 28 Janeiro

\section{CONFERÊNCIAS:}

Tertúlias "Química e Sociedade"Espaço de divulgação científica, discussão e interactividade em torno de um tema introduzido por oradores convidados, com o objectivo de demonstrar a importância basilar da Química na Sociedade. O ambiente é informal e a iniciativa destina-se a toda a Sociedade (comunidade estudantil e público em geral).

A química que existe entre nós é só amor? Ou também ajuda a economia? - José Artur Martinho Simões (ITQB;FCUL) - CM Évora - 28 Janeiro
A Química vista por...Dorothy Hodgkin, prémio Nobel" - Raquel Gonçalves Maia - 28 Janeiro, 15h, Anfiteatro DQB FCUP

Química e Saúde - Luís G. Arnaut (FCT/UC) - 16 Fevereiro

Química e as Novas Tecnologias Elvira Fortunato (FCT/UNL) - $25 \mathrm{Fe}$ vereiro

Química nos produtos de limpeza doméstica e higiene pessoal - Jorge Salvado (Unilever) - 16 Março

A (R)Evolução dos Materiais no século XXI - Elvira Fortunato (FCT/ UNL) - 25 Março

A Química do Amor - Paulo Ribeiro Claro (UA) - 15 Abril

Portais Dedicados: Lançamento do Site www.iyc2011.uevora.pt - 28 Janeiro

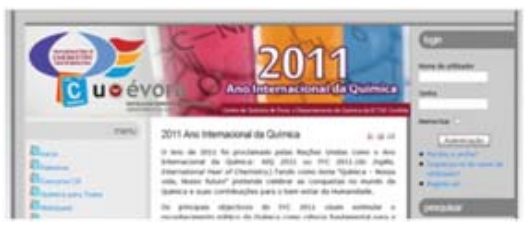

Site www.iyc2011.uevora.pt

ExposiçõEs e outros Eventos: Cerimónia de Abertura do Ano Internacional da Química 2011 na Universidade de Évora - Com o objectivo de assinalar o Ano Internacional da Química, o Centro de Química de Évora (CQE) e o Departamento de Química da Escola de Ciências e Tecnologia da Universidade de Évora (DQUI/ECTUE) realizaram uma série de actividades comemorativas, nomeadamente, a Cerimónia de Abertura do Ano Internacional da Química 2011, no dia 28 de Janeiro, no Salão Nobre da Câmara Municipal de Évora.

A cerimónia de abertura contou com breves intervenções dos seguintes Professores Doutores: Peter Carrott (Director do Centro de Química de Évora); João Nabais (Director do Departamento de Química da ECTUE); Paulo Quaresma (Director da Escola de Ciências e Tecnologia da Universidade de Évora - ECTUE); Júlio Cruz Morais Presidente do Conselho Científico da ECTUE); José Manuel Caetano (Vice-Reitor da Universidade de Évora); José Artur Martinho Simões (Vice-Presidente da Comissão $\mathrm{Na}$ cional do Ano Internacional da Quími-

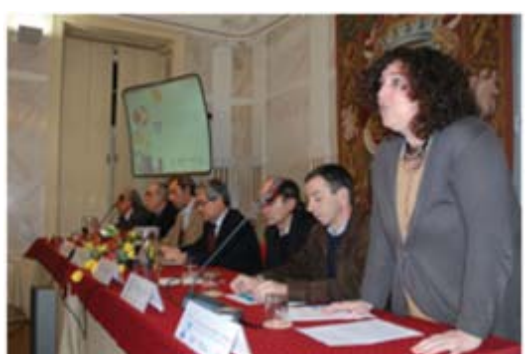

Cerimónia de Abertura do AIQ na Univ. Évora

ca 2011 / Centenário da Sociedade) e de Cláudia Sousa Pereira (Vereadora da Câmara de Évora).

Livros e Publicações: Newsletter Mensal SPQ

\section{FeVereiro}

AcÇÕES DE FORMAÇÃO / WORKSHOPS: Workshops de formação especializada: De Fevereiro a Dezembro na UBI

Congressos: Encontro Nacional de Nanotoxicologia (E2N 2011) - 7 e 8 Fevereiro - Lisboa. Desenvolvimento neste número do QUÍMICA.

Olimpíadas / Concursos: Lançamento Concurso CSI - Compreender, Saber e Investigar a Química - Universidade de Évora - Concurso destinado a alunos do ensino secundário em que os participantes devem elaborar um trabaIho cujo tema central é a Química e a sua presença na vida quotidiana.

Esta iniciativa tem como objectivos fomentar o interesse pela Química, estimular o espírito de iniciativa, criatividade e literacia científica dos alunos, bem como, demonstrar a importância central da Química na Sociedade Moderna. De 8 de Fevereiro a 15 de Maio

Portals Dedicados: Página facebook para divulgação AIQ Lançamento: 8 Fevereiro

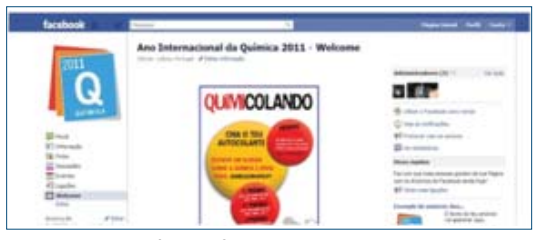

Página facebook do AIQ

CONFERÊNCIAS:

With a little help from Computational Chemistry - Maria José Calhorda. FCUL - 9 Fevereiro 
CONGRESSOS: Jornadas de Electroquímica e Inovação (e-inov) - 11 Fevereiro - Faro. Desenvolvimento neste número do QUÍMICA.

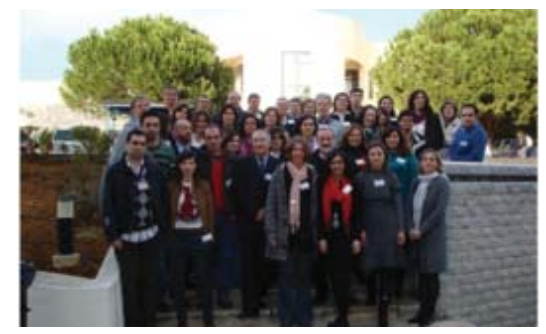

Fotografia de Grupo

CONFERÊnCIAS: A Química do Amor - Café de Ciência - A Química do Amor é um "café de ciência" em torno do papel da química no amor romântico, que inclui uma apresentação curta das moléculas envolvidas nas diferentes fases do amor e termina com uma discussão participada sobre a química, a ciência e a vida.

A actividade é normalmente desenvolvida num ambiente informal de café, para cerca de 20-40 participantes. O assunto é apresentado pelo cientista convidado nos primeiros 15-20 minutos, com ênfase nos resultados experimentais relacionados com o efeito dos compostos químicos no nosso comportamento. A apresentação está concebida para estimular a curiosidade e deixa questões em aberto para a discussão posterior. A discussão é normalmente muito participada, devido ao interesse natural do tema. Esta actividade está a ser oferecida a escolas secundárias e autarquias, com o objectivo de estimular a celebração do Ano Internacional da Química ao nível das comunidades locais.

Fábrica CCV Aveiro - 14 Fevereiro ES Albergaria - 23 Fevereiro

ES Homem Cristo, Aveiro - Março

ES Bento Carqueja, Oliveira de Azeméis - Março

ES Mário Sacramento, Aveiro - 27 Abril

DIVULGaÇÃO: Carteira de Palestras da SPQ - 14 Fevereiro

Actividades LABORATORIAIS / Visitas DE ESTUDO: Laboratórios Abertos 2011/Laboratórios Abertos Júnior 2011 - Nos dias 14 a 18 de Fevereiro realizaram-se, mais uma vez, os Laboratórios Abertos no IST UTL! Contaram com a presença de cen-

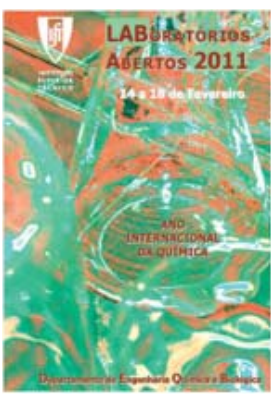

tenas de jovens sedentos de curiosidade para conhecer a universidade e o curso de Engenharia Química e Engenharia Biológica.

Foi uma óptima oportunidade para contactar com os jovens que num futuro virão a enfrentar os mesmos desafios que todos nos deparámos quando chegámos à faculdade.

Este ano houve, no entanto, uma novidade. Estes laboratórios estarão abertos também a alunos mais novos, desde o $5^{\circ}$ até ao $9^{\circ}$ ano, para que lhes possa ser incutido o "bichi-

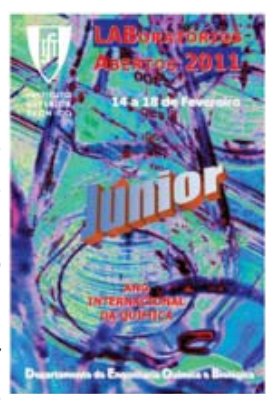
nho" pela Química e pela Área das Ciências Biológicas e Bioengenharias, bem cedo.

\section{EXPOSIÇÕES E OUTROS EvENTOS:}

Dia da Química - O "Dia da Química" colocou cerca de 60 alunos finalistas do ensino secundário em contacto com a comunidade científica e docente do Departamento de Química da UA e com um programa de actividades que se pretende estimulante e informativo. Este programa englobou curtas palestras sobre assuntos científicos actuais, debates sobre temas científicos e saídas profissionais, actividades lúdicas de familiarização com a UA, e demonstrações de Química.

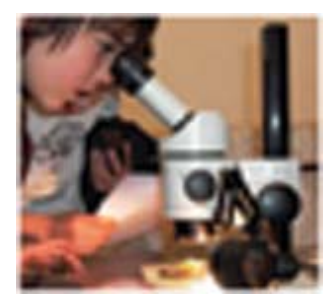

Os alunos participantes foram seleccionados pelos respectivos professores, para os quais está preparado um programa de actividades paralelo - que inclui uma sessão de planeamento de actividades a realizar no âmbito do "Ano Internacional da Química”. - Dep Química UA; 16 Fevereiro

Exposição Artesãos do Século XXI - 14 a 18 Fevereiro, DEQB IST
CONFERÊNCIAS:

NMR: a flagship in moving the frontiers of biological science - Ivano Bertini, CERM-Università degli Studi di Firenze, Italy

16 Fevereiro, FCT UNL

EXPOSIÇÕES E OUTROS EVENTOS: Ciência em Família: Descobre as Moléculas, Sérgio Melo - Nesta actividade propomos-te que conheças moléculas que dão cheiro e cor. Verás como de forma simples conseguimos produzir cheiros. Verás também de onde vêm ou onde se produzem moléculas com cor; algumas com certeza já conheces: nos smarties, nas tuas calças ou até no teu sangue. Anda daí, vem descobrir as moléculas no Ano Internacional da Química!

Local: Museu da Ciência da Universidade de Coimbra; 20 Fevereiro

CONFERÊNCIAS: "A Química vista por... um físico" - Carlos Fiolhais Local: DQB FCUP; 25 Fevereiro

Livros e Publicações: Newsletter Mensal SPQ

\section{MaRço}

AcÇÕES DE FORMAÇÃO / WORKSHOPS: Workshop sobre pigmentos e tinturaria tradicional - O Laboratório HERCULES em parceria com o Museu de Évora promoveu, durante o mês de Março, diversos workshops sobre pigmentos e tinturaria tradicional dirigidos a jovens de diferentes faixas etárias. $\mathrm{E}$ como de pequenino se torce o pepino, - HERCULES pretendeu com estas actividades sensibilizar crianças de Jardins de Infância e alunos de várias escolas para importância da Química no nosso Património.

EXPOSIÇÕES E OUTROS EVENTOS: Estímulo à Criatividade e à Qualidade na Actividade de Investigação Fundação Calouste Gulbenkian | Serviço de Ciência.

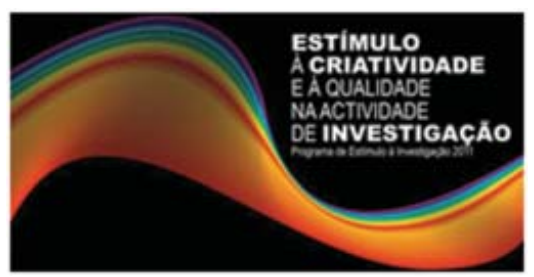


Estão abertas as candidaturas para o Programa de Estímulo à Investigação 2011. O Programa foi instituído pelo Serviço de Ciência da Fundação Calouste Gulbenkian com o objectivo de estimular entre os mais novos a criatividade e a qualidade na actividade de investigação científica. Distingue anualmente propostas de investigação de elevado potencial em áreas científicas e apoia a sua execução em centros de investigação portugueses. As candidaturas devem ser apresentadas até dia 23 de Setembro.

Livros e Publicações: Magnificent Molecules - Secção de QT e BC do DQB FCUP

Olimpíadas / Concursos: Lançamento Concurso literário "QUÍMICA EM LETRAS" - Ligar o mundo da escrita ao mundo da ciência...Escrever um conto, em Português, onde o tema central seja a Química - é este o grande desafio do concurso literário.

ExPOSIÇÕES E OUTROS EVENTOS: Exposição "Moléculas Magníficas" Fundação José Rodrigues, de Março a Junho

ActiVIDADES LABORATORIAIS / VISITAS DE Estudo: A Química e a Cidade O projecto consiste numa mostra de trabalhos experimentais, que se centra no papel relevante que a Química tem na sociedade actual e na Cidade. Esta iniciativa foi dirigida a alunos do $3^{\circ}$ Ciclo do Ensino Básico e Secundário. Foram efectuadas experiências de simulação de chuvas ácidas e do seu efeito nas rochas calcárias, nomeadamente em alguns monumentos da cidade, de tratamento de águas poluídas (por processos físicos e químicos); de análise de oxigénio e pH em águas de diferentes proveniências e avaliação da sua qualidade, etc. 1 e 2 de Março - DQ-FCTUC.

ExPOSIÇÕES E OUTROS EVENTOS: “Ano Internacional da Química na Semana Profissão: Engenheiro 2011" - A "Semana Profissão: Engenheiro" apresentou mais de 60 actividades para alunos, professores e psicólogos do secundário, e reuniu professores, investigadores e estudantes da FEUP em apresentações e demonstrações, oferecendo assim uma oportunidade única de conhecer a Engenharia por dentro. Este foi também o momento ideal para ficar a saber mais sobre os cursos da FEUP e as suas saídas profissionais. De 1 a 3 de Março.

\section{CONFERÊNCIAS:}

Intracellular proteolysis: mechanisms, structures and application Robert Huber, Max-Planck Institute of Biochemistry-München, Germany - 2 Março - FCT UNL

À conversa com um Nobel da Química - Em pleno Ano Internacional da Química, o Pavilhão do Conhecimento- Ciência Viva recebeu o Prémio Nobel da Química Robert Huber. Huber foi distinguido pela academia sueca em 1988, juntamente com Hartmut Michel e Johann Deisenhofer, por ter revelado com grande detalhe os aspectos estruturais tridimensionais de uma proteína essencial para a fotossíntese em bactérias púrpuras - 2 Março - Pavilhão do Conhecimento Ciência Viva

Actividades LaboratoriaIS / VISITAS DE ESTUDO: Dia Aberto IPB - Este dia teve como objectivo abrir as portas ao público em geral e divulgar as áreas de actividade técnico-científica e a oferta formativa disponível no IPB, permitindo à comunidade, e aos alunos do Ensino Secundário, em particular, um contacto privilegiado com o Ensino Superior.

Data: 2 Março

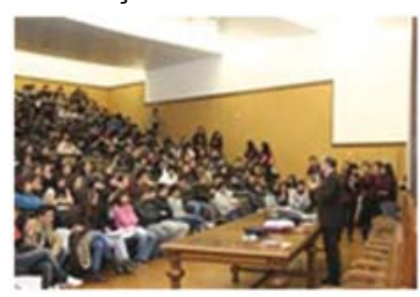

ACÇÕES DE FORMAÇÃO / WORKSHOPS: Curso / Workshop - Segurança Química; 4as feiras de tarde, durante o mês de Março - DQB FCUP Início: 2 Março

Olimpíadas / Concursos: MiniQui No âmbito da XIII Semana Cultural da Universidade de Coimbra e integrado nas actividades do QUI365 para celebrar o Ano Internacional da Química, - Departamento de Química realizou uma exposição com um conjunto de experiências de Química cuja temática geral foi "Reinventar a Cidade".
Foi dirigida a crianças do $3^{\circ}-4^{\circ}$ ano de escolaridade para que possam compreender, mexendo, ouvindo, vendo e cheirando, como a química faz parte do nosso dia-a-dia. O objectivo desta iniciativa foi motivar os alunos para a aprendizagem das áreas científicas.

3 e 4 de Março - DQ-FCTUC

\section{CONFERÊNCIAS:}

“A Química e nós" - As conferências são realizadas pelos docentes do Departamento de Química da FCTUC focalizando os diversos aspectos com que esta Ciência contribuiu e contribui para a nossa Sociedade. O Público alvo são os alunos do Ensino Básico e Secundário.

Conferência Percursos Químicos Sérgio Rodrigues - 3 Março

Conferência A Química é Verde Mariette Pereira - 3 Março

Conferência A Essência das Essências - Marta Piñeiro - 4 Março

Conferência A Génese Química do Medicamento - Arménio Serra - 4 Março

EXPOSIÇÕES E OUTROS EVENTOS: Café, Livros e Ciência:

O Sistema Periódico - Primo Levi, apresentado por Sebastião Formosinho - 3 Março - Museu da Ciência Coimbra

Os Elementos Químicos e a Vida apresentado por João José Fraústo da Silva e José Armando da Silva - 7 Abril - Fábrica CCVA

OlimpíadAs / Concursos: Semifinais Olimpíadas de Química Mais - 12 Março - DQ FCTUC; FCUP; IST UTL Desenvolvimento neste número do QUÍMICA.

Exposições E OUTROS EVEntos: Semana das Ciências Agrárias

14 a 17 Março - ESA-IPB

CONFERÊNCIAS: Porphyrinoids: some insights into Molecular Aggregation and Photoreactivity - Sílvia M. B. Costa, CQE/IST - Lisboa 16 Março - FCT UNL

Livros e Publicações: Lançamento do livro "Os Elementos Químicos e a Vida" de José Armando Luísa da Silva e João José Fraústo da Silva. 
O livro foi apresentado, no dia 17 de Março, por José J. G. Moura, professor catedrático do Departamento de Química da Faculdade de Ciências e Tecnologia da Universidade Nova de Lisboa.

EXPOSIÇÕES E OUTROS EVENTOS: 9a Mostra da Universidade do Porto - A Mostra de Ciência, Ensino e Inovação da U.Porto é o espaço ideal para se perceber a diversidade da oferta formativa da Universidade do Porto, mas também para a exploração, de forma interactiva, de variados aspectos do conhecimento científico. Foram quatro dias em que a Ciência e o Conhecimento estavam de portas abertas para a sociedade, num espaço pensado para as escolas e os seus estudantes, mas também para as famílias e os simples...curiosos.

17 a 20 Março - Pavilhão Rosa Mota

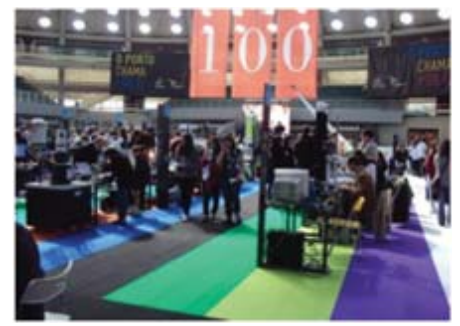

$9^{a}$ Mostra da UP

Olimpíadas / Concursos:

$7^{\circ}$ Campeonato Nacional de Jogos Matemáticos - Aproveitando o evento, a Área Departamental de Engenharia Química (ADEQ) do ISEL abriu os seus laboratórios à comunidade escolar participante. Os alunos e professores envolvidos neste Campeonato tiveram oportunidade de visitar e interagir com as actividades laboratoriais a decorrer nos vários laboratórios da ADEQ. - 18 Março - ISEL

Jornadas de Engenharia Química e Biológica 2011 - De 21 a 25 Março Salão Nobre IST

Jornadas de Bioquímica - 23 e 24 Março, UTAD

ExPOSIÇÕES E OUTROS EVENTOS: Experiência Global e Dia Mundial da Água - Lançamento: 22 Março. Desenvolvimento neste número do QUÍMICA.

Abertura Oficial do Ano Internacional da Química (AIQ) 2011 na UTAD Comemorações do XXV Aniversário da UTAD
Oração de Sapiência - proferida pelo Doutor José Artur Martinho Simões, Professor Catedrático do Departamento de Química e Bioquímica da Faculdade de Ciências da Universidade de Lisboa - 22 Março - UTAD

\section{CONFERÊNCIAS:}

Conferência Prof. Miguel Castanho - Faculdade de Medicina - Universidade de Lisboa - 23 Março - UTAD

A Química vista por... uma gastrónoma molecular - Paulina Mata - 25 Março - DQB FCUP

\section{Expressão Plástica e Artística:}

\section{Substâncias:}

\section{Quorum Ballet}

No ano em que se comemora o Centenário da Universidade de Lisboa e o Ano Internacional da Química, o Quorum Ballet apre-

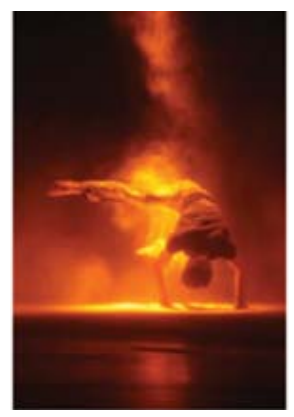
sentou Substân-

cias, uma criação inspirada na ciência química, mais concretamente na estrutura e propriedades de elementos e substâncias. Os bailarinos interagem e reagem entre si dentro de uma perspectiva humana. Através da expressão corporal pretende-se promover o... encontro de duas áreas tipicamente distintas: a ciência e a arte.

Estreia: 25 Março - Aula Magna da Reitoria da Universidade de Lisboa

Repetição do espectáculo:

15 Abril - Teatro Recreios Amadora

29 Abril - Teatro de Vila Real

Actividades Laboratoriais / Visitas DE ESTUDO:

Dia Aberto do ITQB - Tal como nas edições anteriores, esta actividade proporcionou um dia de descoberta, dos 0 aos 99, e a partilha do nosso entusiasmo pelo nosso trabalho.

Este ano, o Dia Aberto foi organizado em torno dos Prémios Nobel da Química. A partir deles falámos da investigação realizada todos os dias no ITQB, na área da química, da bioquímica, da biologia, da biotecnologia.

Data: 26 Março

Dias da UBI - Os Dias da UBI são uma iniciativa destinada a divulgar as capacidades e potencialidades da
Instituição em termos científicos, técnicos e culturais e constituem uma oportunidade para dar a conhecer o ambiente universitário, através de visitas guiadas aos diversos Departamentos, Centros e ainda a outros sectores como a Biblioteca e o Museu. $\mathrm{Na}$ décima quarta edição d'Os Dias da UBI foram apresentadas exposições, conferências, experiências em laboratórios, tecnologias computacionais e multimédia, num conjunto de iniciativas interactivas - 22 a 24 Março

CONFERÊNCIAS: Introdução à Metrologia Química :: TrainMiC

28 e 29 Março - LNEG, S. Mamede Infesta

Livros e Publicações: Boletim SPQ - QUÍMICA 120 - 28 Março

ExPosiçõEs E OUTROS EVENTOS: Cerimónia de Lançamento do Ano Internacional da Química na Solvay 29 Março

CONFEREANCIAS: Towards Targeted Photodynamic Therapy - David Phillips, Imperial College-London, United Kingdom - 30 Março - FCT UNL

EXPOSIÇÕES E OUTROS EVENTOS: Sopas, Caldos e Mezinhas: A química no tempo dos nossos avós - Este projecto consiste na recolha de histórias tradicionais relacionadas com química, mas também com a identificação de conhecimentos empíricos de culinária ou medicina tradicional que possam ter sido usados, ou ainda sejam usados nos nossos dias. Pretendemos ainda recolher textos em forma de provérbio, adivinha ou lengalenga, desde que sejam de raiz popular e estejam relacionados com as diversas áreas da química

Início: 31 Março - Museu da Ciência de Coimbra

Livros e PublicaçõEs: Newsletter Mensal SPQ

ABRIL

EXPOSIÇÕES E OUTROS EVENTOS: Exposição VIDA E OBRA DE MARIA SKLODOWSKA-CURIE e Exposição MARIE CURIE, A LIFE - ITINERAIRE D'UNE FEMME - Exposições sobre a vida e obra desta investiga- 
dora, a primeira mulher a conquistar um Prémio Nobel. Maria Skłodowska Curie: Madame Curie é uma exposição organizada em colaboração com os Arquivos da Academia das Ciências da Polónia, o Museu de Maria Skłodowska Curie, em Varsóvia, e o Museu Curie, em Paris.

Locais: Museu Nogueira da Silva (Braga), Museu da Ciência da Universidade de Coimbra. Irão passar por Aveiro, Vila Real, Lisboa e Porto

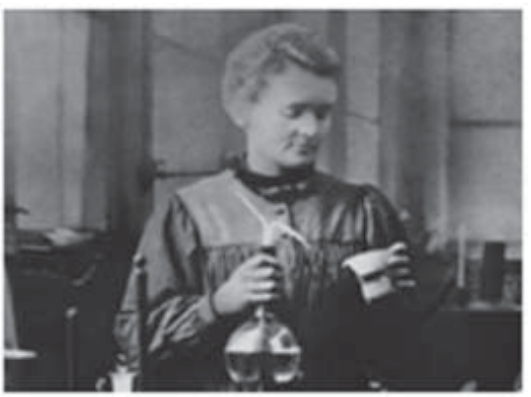

EXPOSIÇÕES E OUTROS EVENTOS: Homenagem aos discípulos portugueses de Marie Curie: Branca Edmée Marques, Mário Silva e Manuel Valadares - Locais: Museu Nogueira da Silva (Braga), Museu da Ciência da Universidade de Coimbra

Gadgets \& Merchandising: Posters de divulgação do AIQ

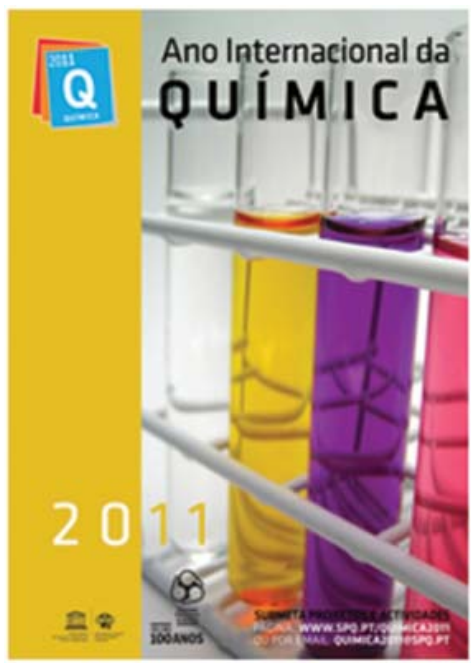

AcÇõES DE FORMAÇÃo / WORKSHOPS: Os cinco Sentidos da Química Workshop de Gastronomia Molecular: dirigido aos professores acompanhantes dos alunos que participam nas Olimpíadas de Química Júnior - 2 Abril - Semifinais (UTAD)

Olimpíadas / Concursos:

Semifinais Olimpíadas de Química Júnior - 2 Abril - UMinho; UTAD;
FCUP; DQ UA; FCTUC; UBI; DQB FCUL; IST UTL; FCT UNL; FCT UAIg. Desenvolvimento neste número do QUÍMICA.

Jornadas: Química - A Ciência que muda o Mundo - 6 Abril - UTAD

Actividades LaboratoriaIS / Visitas DE Estudo: Open Week na ADEQ ISEL - Actividade vocacionada para alunos do ensino básico, $3^{\circ}$ ciclo e secundário. Foram realizadas visitas guiadas aos laboratórios, onde se apresentaram experiências de carácter interactivo. Paralelamente, foram disponibilizadas algumas experiências para serem realizadas pelos próprios. Data: 4 a 8 de Abril

ExPOSIÇÕES E OUTROS EVENTOS: “Marie Curie, 1867/1934. Uma Vida, Itinerário de uma Mulher" - A exposição apresenta uma visão da personalidade de Marie Curie, a consagrada cientista que se destacou pelo contributo de excepção no mundo da Química, sendo a primeira mulher a receber um Prémio Nobel e a primeira pessoa a receber aquele prémio pela segunda vez. Em 1903, Marie Curie partilhou com o marido, Pierre Curie, e com Henri Becquerel o Prémio Nobel da Física graças aos estudos do fenómeno da radioactividade e, sete anos mais tarde, a descoberta do rádio e do polónio, o isolamento do rádio e o estudo daquele elemento e dos seus compostos valeram-Ihe o Prémio Nobel da Química.

De 4 a 28 de Abril - Braga Parque

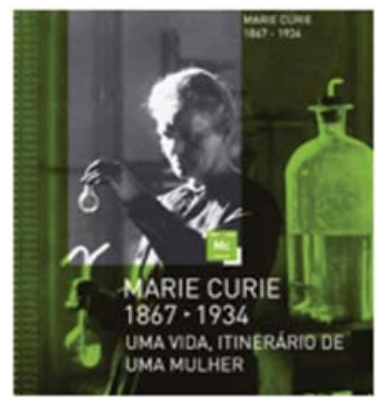

Cartaz da Exposição "Marie Curie, 1867/1934. Uma Vida, Itinerário de uma Mulher"

Expressão Plástica e Artística: Misturar Química com Teatro Quimicomics, pelo "Encerrado para Obras". O humor e o duplo sentido das palavras no palco da Química, por uma companhia de teatro.

5 Abril - Exploratório, Centro Ciência Viva de Coimbra
Actividades LaboratoriaIS / Visitas DE Estudo: Apreender Ciência Alimentar

Dia Aberto - X Jornadas de Divulgação do Ensino Superior Público do Distrito de Vila Real

Experiências na área de Análise Sensorial: Chocolates, batata frita e sumos

Experiência na área da Química Alimentar: Quantificação da actividade antioxidante de alimentos; Escurecimento enzimático de alimentos Para alunos do $11^{\circ}$ e $12^{\circ}$ anos

- 5 Abril - UTAD

CONFERÊNCIAS:

Palestra Marie Curie: Transcender as Convenções - Prof ${ }^{a}$ Raquel Gonçalves (FCUL) - 5 Abril - Reitoria da UMinho

Palestra Radiopharmaceutical Development and Evaluation. Radiotracers for the study of the translocator protein", Prof ${ }^{a}$ Filomena Mattner, Investigadora de ANSTO Life Sciences, Sydney, Austrália - 6 Abril - UBI

Olimpíadas / Concursos: Química A Ciência que muda o mundo 6 Abril - UTAD

EXPOSIÇÕES E OUTROS EvEnTOS: No Tempo de Marie Curie

Exposição co-organizada pela Escola Secundária Sá de Miranda e pelo DQ da UMinho. De 8 de Abril a 31 de Maio na ES Sá de Miranda.

CONFEREANCIAS: Sacred Chambers: Laboratories through Books and Art - Santiago Alvarez, Universitat de Barcelona, Spain - 13 Abril - FCT UNL

Expressão Plástica e Artística: "Radiação - História de Maria Skłodowska-Curie" de Kazimierz Braun e interpretada pelo Polish Theatre of Toronto, no Canadá.

Local: Theatro Circo; Data: 14 Abril

Desenvolvimento neste número do QUÍMICA.

Olimpíadas / Concursos: Q-Arte Concurso de desenho/esquema/logótipo/foto a expor na FCUL - 2011. O desenho terá um título sugestivo e será acompanhado de um pequeno ensaio com o máximo 300 palavras alusivo ao tema.

Lançamento: 18 Abril 
CONFERÊNCIAS: À conversa com um Nobel da Química - Ada Yonath No dia 19 de Abril, o Pavilhão do Conhecimento - Ciência Viva recebeu Ada Yonath, Prémio Nobel da Química em 2009. A cientista esteve à conversa com o Falar Global, da SIC Notícias, e com os visitantes, que tiveram também a oportunidade de lhe colocar questões.

Ada Yonath esteve em Portugal a convite da Universidade Nova de Lisboa, tendo dado uma palestra na Reitoria desta Universidade (18 de Abril, 12h) e outra no Porto, no IBMC (19 de Abril, 16h 30). Esteve também disponível para responder às perguntas dos investigadores numa sessão no ITQB (18 de Abril, 16h)

Expressão Plástica e Artística: Tabela Periódica - A Tabela Periódica dos Elementos pintada nas lajes do pátio do edifício C8 da FCUL, um elemento por laje num total de aproximadamente $90 \mathrm{~m}^{2}$.

19 Abril - Alunos e público em geral FCUL, Ed. C8 (pátio)

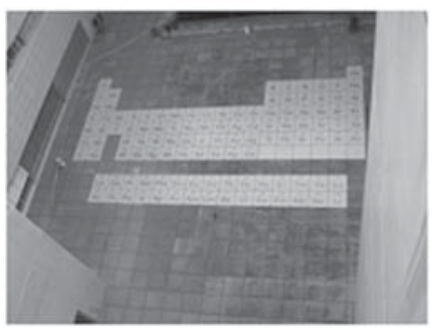

A Tabela Periódica no Pátio da FCUL

Olimpíadas / Concursos: Concurso de autocolantes SPQ - O objectivo deste concurso é a elaboração de três autocolantes diferentes no âmbito do Ano Internacional da Química 2011. Pretende-se desta forma realçar a importância desta ciência através da criatividade dos alunos, propondoIhes que escrevam um slogan sobre a Química. Concurso em vigor entre 20 de Abril e 20 de Maio

CONFERÊNCIAS: Solid-state NMR methods applied to pharmaceuticals Luís Mafra, CICECO-Universidade de Aveiro - 27 Abril - FCT UNL

\section{Olimpíadas / Concursos:}

V Jornadas de Bioquímica - As jornadas foram organizadas pelos alunos da Licenciatura em Bioquímica da Universidade de Aveiro e contam com a colaboração do Departamento de Química - 27 Abril - DQ UAveiro

Jornadas de Bioquímica - 27 Abril, DQ UA

Produtos Audiovisuais: Entrevista ao Doutor Mário Nuno Berberan e Santos - Antena 1

Tema: Tradução e Apresentação do Livro "A História Química de uma Vela" de Michael Faraday

Data: 28 Abril

Livros e Publicações: Apresentação da Obra "A História Química de Uma Vela"- Michael Faraday - Apresentação pública da obra A História Química de uma Vela, de Michael Faraday, traduzida por Maria Isabel Prata e Sérgio Rodrigues.
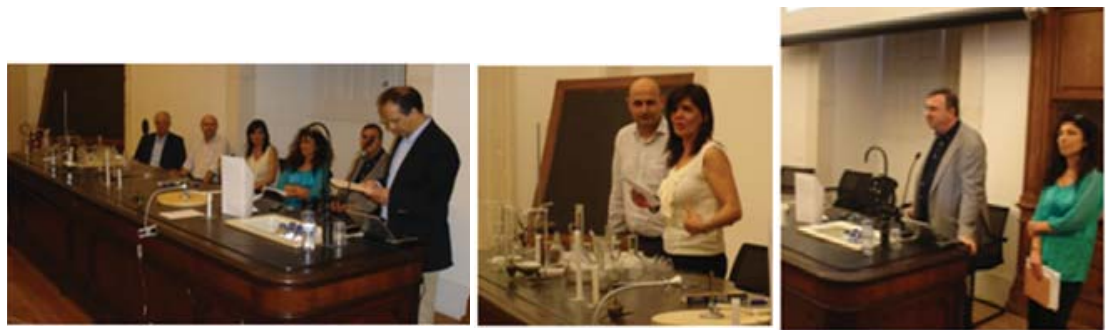

Da esquerda para a direita: Mesa de Honra; Sérgio Rodrigues e Maria Isabel Prata, tradutores do livro; Mário Nuno Berberan e Santos e Palmira F. Silva
A apresentação do livro esteve a cargo de Palmira F. Silva e Mário Nuno componente experimental baseada nas aulas de Faraday.

ConferÊnCIAS: Palestra Mário Silva: Um Físico Português no Laboratório Curie - Prof. Décio Martins (FCTUC) - 28 Abril - Escola de Ciências da UMinho

CONFERÊNCIA: "A Química vista por... um membro do Parlamento" - José Ferreira Gomes - 29 Abril DQB FCUP

Exposições e OUtros Eventos: A minha escola na Universidade Um encontro de âmbito nacional de escolas do $3^{\circ}$ ciclo e secundário. Nesta iniciativa, cada escola participa com a apresentação de trabalhos realizados no âmbito da Química, com vários formatos, incluindo comunicações orais e em painel, uma exposição de fotografia e realização de obras de teatro. Data: 29 Abril - DQ FCTUC

LiVros e Publicações: Newsletter Mensal SPQ

Vanda Capitolino (quimica2011@spq.pt) www.spq.pt/quimica2011 Berberan e foi acompanhado por uma

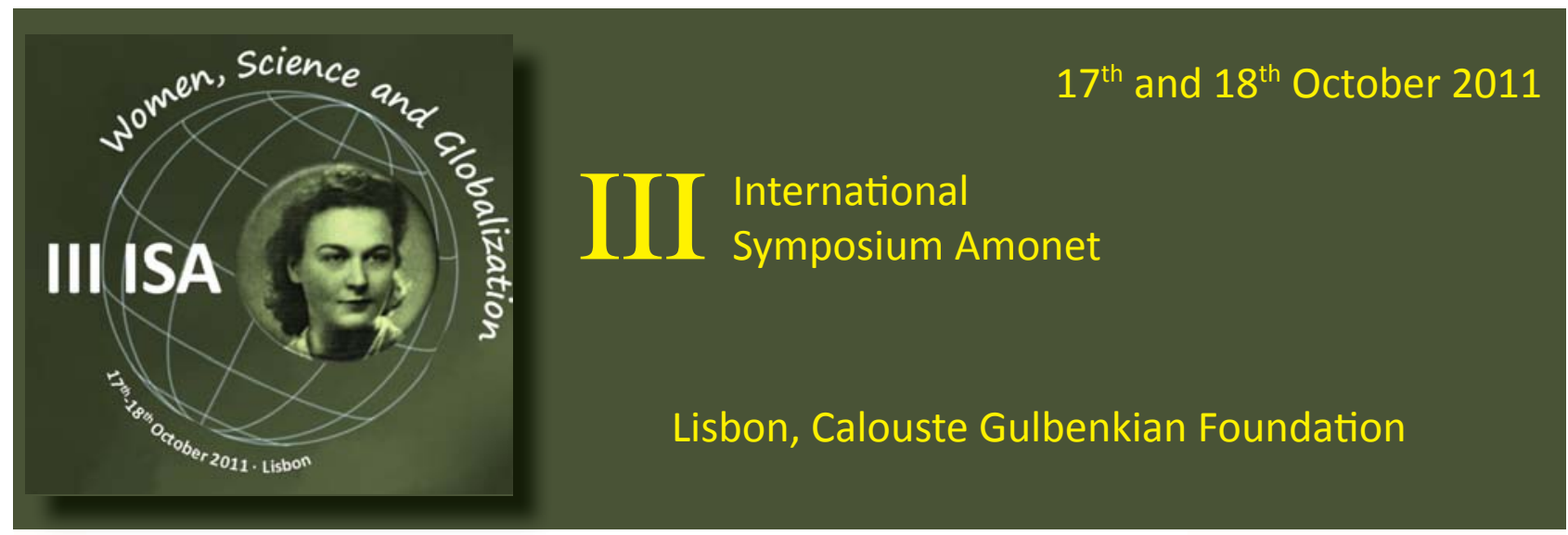

